\title{
Claves de Cortázar en un Libro Olvidado: Buenos Aires. Buenos Aires.
}

Transcurrido bastante tiempo desde su publicación (1968), una obra de Julio.Cortázar corre el riesgo de quedar olvidada por la crítica. Si se tratara de otro autor, nos resistiríamos a considerarla, pero en Cortázar confluyen varias justificaciones. En primer lugar: la unicidad de toda su literatura. En todo estadio de su producción puede estar la síntesis, cima y explicación del resto. El mismo Cortázar nos recuerda al final de una de las numerosas reediciones de Final del juego: "fatuo sería el escritor que creyera haber dejado definitivamente atrás una etapa de su obra. En cualquier página futura puede estar esperándonos una nueva página pasada". ${ }^{1}$ Buenos Aires. Butenos Aires ${ }^{2}$ nos parece ampliamente significativa para esclarecer algunos aspectos de su visión de la literatura, de la síntesis sutil entre su profundo sentido porteño y su rotunda universalidad: "Decir Buenos Aires es decir el mundo, ahora" (p. 52). En segundo lugar: la escasez, más que abundancia, de su producción. En Cortázar no hay una línea superflua y pareceria que ello se debe más que nada a la propia voluntad del autor: "soy uno de los escritores más fiacas que ha dado la Argentina, excelsa sin embargo en ese terreno como lo prueban Guido y Spano y Enrique Banchs entre otros muchos. Desafío a cualquiera que demuestre que he escrito una sola línea por razones de compromisos editoriales". ${ }^{3}$

La obra a la que nos referimos ba sido recibida por la crítica con una indiferencia casi total, nunca justificada por razones económicas. ${ }^{4} \mathrm{El}$ texto, en colaboración con las fotografías de Alicia D'Amico y. Sara Facio, pre-

\footnotetext{
1 Final de juego (Buenos Aires: Sudamericana, 1970, 11a. edición), p. 197.

2 Buenos Aires: Sudamericana, 1968. Todas las citas son de esta edición.

3 Hispamérica, I, 2 (diciembre 1972), p. 57.

- Una de las pocas excepciones sería la mención de Rafael Conte en Lenguaje y violencia (Madrid: Al-Borak, 1972, p. 139: "donde tal vez la prosa de Cortázar ha encontuado acentos inolvidables", También le dedica unas lineas Malva Filer en Los mundos de Julio Cortázar (N.Y.: Las Américas, 1970), pp. 104-105.
} 
senta la confluencia de la mirada de Cortázar y el objetivo de los fotógrafos. La ciudad se congela en "esta baraja de espejos que detienen la hora múltiple en el azogue de unas páginas" (p. 19).

\section{REPULSA DE IA SUPERFICIALIDAD.}

Cortázar señala lo que considera como contrario a la esencia de la ciudad, al indicar que precisamente "Sara y Alicia han fotografiado Buenos Aires con un soberano techazo de temas monumentales, de itinerarios pintorescos o insólitos" (p. 23), ya que la ciudad es otra cosa muy distinta de lo que se muestra en las guías de turismo. Cortázar se dedica a desechar lo superfluo, postizo, enmascarado: "de la ciudad tenemos los párpados, la piel, la risa o el rechazo, la moviente superficie de los dias" (p. 45). Se pregunta: "¿Quién puede jactarse de conocer más que las fachadas que dan sobre esas calles porteñas, y unas pocas calles por las que infinitamente fluye su sangre cotidiana?" (p. 45). Por ese camino, al ver de Cortázar, no logramos penetrar en la región nuclear del alma ciudadana, ya que "estamos fuera, irremisiblemente fuera de las cosas que hacen la ciudad, y deśde esa exclusión inventamos un contacto y una permanencia y un conocimiento con la secreta y admirable desesperación con que lo hemos inventado todo" (p. 45). Lo que en realidad constituye el soporte animico de una ciudad como Buenos Aires no puede verse alterado por planes urbanísticos circunstanciales; la urbe sigue con su personalidad incólume, "sin que ningún cambio exterior lo sobresalte o lo ultraje [al autor], porque ya no hay novedad o catástrofe municipal que puedan cambiar el verdadero encuentro que ocurre en otra región indecible" (p. 25). Nótese que Buenos Aires desaparece físicamente en la segunda parte de Rayzlela $a^{5}$ y queda personificada en la lengua de los protagonistas. Horacio, Traveler y Talita sustituyen con sus diálogos la ciudad trocada en el circo y el manicomio. Para llegar a esa dimensión secreta, intrahistórica, hay que rechazar ciertos métodos empíricos y estadísticos, "entendiendo y entendiéndose desde una visión y un lenguaje que sada tienen que ver con la historia y la circunstancia" (p. 46).

\section{BUENoS AIRES Y LA LITERATURA}

La ciudad es siempre la misma para el que no quiere y no está dispuesto a ir más allá del cemento y del asfalto. Julio Cortázar tevela sus

5 Buenos Aires: Sudamericana, 1963. 
admiraciones literarias: "Trato de imaginar al novelista de Buenos Aires, a la mujer o al hombre que un día obligarán a la ciudad a rendir sus más secretas llaves, como ya estas imágenes rinden tantas puertas. Parado en una esquina, con su bufanda y su chambergo, Roberto Arlt fuma y espeta. Cuando pasen esa mujer o ese hombre, él los mirará largamente antes de irse. El vigia podrá descansar" (p. 194). En rigor, Julio Cortázar intuye perfectamente que él también ha estado en el mismo camino de Arlt, pero con otros métodos, sin costumbrismo. ¿Qué es entonces Buenos Aires para él? La respuesta es mucho más sencilla que los monumentos y edificios urbanos, pero, al mismo tiempo, resulta más difícil de captar: "los ojos de esa chiquita que sale de la escuela, el atorrante que duerme sobre los tubos de fibrocemento, la viejita sentada en la vereda, la barra de la esquina, los tipos que hacen cola en el baño público, la gente" ( $p$. 25). ¿Cómo podemos llegar a asimilar esta esencia? Para nuestro autor, el camino es obvio: "sólo así se entrega alguna vez a su habitante, cuando se la escala desde el sueño o el recuerdo, cuando se la posee con las armas de la imaginación y del mito" (p.46). El conocimiento de la ciudad es un proceso, nunca es estático, sino que se logra mediante el largo recorrido de la lenta creación literaria.

En este libro, Cortázar tiene sutiles incursiones en el sector que parecía reservado al ensayismo intuitivo, a la indagación nacional de los años treinta argentinos. Resabios de Martínez Estrada se deslizan por estas páginas: "Rechazados desde el fondo de los tiempos por la naturaleza venenosa, la hemos inventado amiga y servidora; rechazados pur la ciudad que no es de nadie, la hemos poseído por el amor, por la violencia, por el vagabundeo, por una oscura poesía de bares y trabajo'" (pp. 45-46). Raúl Scalabrini Ortiz podría haber incluído estas líneas en $E l$ bombre que está solo $y$ espera: ${ }^{6}$ "Ciudad moderna, sus domingos tienen esa penetrante tristeza enmascarada con gritos y el mejor traje, tienen la caída de hombros del que vagamente busca escapar a la alienación de la semana y de la vida, encontrar una reconciliación que todo le niega y que sólo la esperanza vestida de gol o de batacazo le muestra desde lejos". (p. 181). Alejado en sus primeras obras de la problemática argentina e hispanoamericana, se observa una progresiva y más honda preocupación por los temas de su cultura en las grandes obras posteriores. El camino de Cortázar es por lo tanto distinto al de otros que saltan de. los temas locales a la universalidad. El creador de los cronopios comienza tras la senda fatídica de Borges, quien ya habia abạndonado la

6 Buenọs Aires: Gleizer, 1931. 
poesía con temas de barrio, esquina y compadre, mitificándolos más tarde en sus cuentos fantásticos.

\section{Literatura y Desarraigo}

A juicio de H. A. Murena, ${ }^{7}$ el argentino $\rightarrow$ el americano, por extensión- está constituido por el balanceo de dos arquetipos: uno desea salir del país, en donde se siente castigado, y el otro se aferra a la tierra. El primero se solaza con cualquier muestra de cultura extraña, y el segundo se trueca en un ultranacionalista. El que anhela poder huir de la maldición austral considera que la cultura todavía está en Europa: el desarraigo es el resultado. Cortázar reconoce que también se sintió atacado por el mismo mal: "inventó espejos que adelantaban o atrasaban, [...] no pidió ni agradeció que le dieran el pan nuestro de las imágenes de cada día, prefiriendo elegir el reflejo incierto de otras ópticas" (p. 19). Su corta obra crítica de los primeros años había quedado reducida a estudios sobre literatura inglesa y francesa. En un camino que claramente empieza con Alina Reyes, de "Lejana" y que cesa un tanto en "Las puertas del cielo" -ambos de Bestiario -, el autor está creando seres que se sienten dominados por el desarraigo. Nuestro autor repasa brevemente su vida y "mira desconfiado un Buenos Aires que había sido repulsa y enajenación" (p. 23). El rechazo de la realidad inmediata está plasmado en "La banda" y en "Las ménades" — de $F$ nal del juego-y sobre todo en Los premios, ${ }^{\circ}$ con la cima en las acciones de Horacio en Rayuela, que se repite en lo fundamental de "El otro cielo" de Todos los fuegos el fuego: ${ }^{10}$ todos ellos tienen varios motivos para tratar de abandonar un país que resulta intolerable, aunque ellos no sepan exactamente por qué. Incluso para el mismo autor, este aspecto es muy complejo y al mismo tiempo bastante simple. En la misma carta a Hispamérica, contesta a David Viñas: "Yo no me vine a París para santificar nada, sino porque me ahogaba dentro de un peronismo que era incapaz de comprender en 1951, cuando un altoparlante de la esquina de mi casa me impedía escuchar los cuartetos de Bela Bartok; hoy puedo muy bien escuchar a Bartok (y lo hago) sin que un altoparlante con slogans políticos me parezca un atentado al individuo". ${ }^{11}$

7 El pecado original de América (Buenos Aires: Sur, 1954),

8 Buenos Aires: Sudamericana, 1957.

9 Buenos Aires: Sudamericana, 1960.

10 Buenos Aires: Sudamericana, 1968.

11 Hispamérica, I, 2 (diciembre 1972), p. 56. 
Lo cierto es que el autor abandonó Argentina un día y en su voluntario transterramiento escribió lo mejor de su producción. Sus personajes miran hacia atrás muchas veces. Cortázar recuerda los pasados tiempos porteños: "Ahora sabe, por más viejo y distante, que no amó a la gente de la ciudad como la aman estas muchachas, él no vivió un Buenos Aires de barra o de partido, de club o de noviazgo, un Buenos Aires caminado y escupido y entrañado, él no se acercó al canillita con algo más que la moneda y la orden, a la mujer con algo más que el deseo y la demanda" (p. 23). Por alienación, por rechazo total de la vulgar realidad que lo envolvía, el autor resuelve un día materializar el sueño del que considera estar castigado en el solar americano. La humanidad, que juzgaba ausente a su alrededor, la creyó ubicada en el otro continente: "Tuvo que irse, tuvo que reconciliarse con el prójimo en horas de amargas querellas, hospitales y pasiones, tuvo que participar de ese misterioso tráfico de la sangre que fluye de las venas de uno para correr en las del otro, en las de todos los otros" (p. 23). Para Julio Cortázar en plena confesión, este salto no fue más que espejismo y el remedio pareció no encontrarse: "tuvo que viajar una vez hasta las islas para comprender que no man is an island, y sólo entonces comprender, empezó a vivir más cerca de la vida' '(p. 23). El autor confiesa a Harss, ${ }^{12}$ sin ambages, su alienación humana hasta el momento de escribir "El perseguidor": es precisamente tras el exilio de 1951 cuando el contacto con el hombre se hace notar más. En La vuelta al día en ocbenta mundos'3 escribe el poema "La patria", de 1956, algo que el autor teme que no será bien interpretado, como evidentemente no lo ha sido en su totalidad.

Otros personajes creados por Cortázar han dado salto similar al viejo mundo: el camino se abre con Alina Reyes en "Lejana" y el fracaso final es total; "Una flor amarilla" y "El ídolo de las cícladas" (Final del juego) tienen fin semejante al primero: autodestrucción del personaje. "El móvil" (Final del juego) nos muestra cómo la dureza del compadrito se desmorona en la distancia de la patria. Es, sin embargo, con "Cartas de mamá" (Las armas secretas"4) cuando vemos con mayor claridad cómo la decisión de abandonar Argentina no libera al protagonista de sus problemas de antaño. Los premios terminan en absoluto fracaso de todos los que intentan dejar a un lado su vida anterior: lo aconsejable es seguir la tónica de la mayoría del pasaje y no saltát

12 Los nuestros (Buenos Aires: Sudamericana, 1966),

13 México: Siglo XXI, 1967.

14 Buenos Aires: Sudamericana, 1964, 
a "la popa", a otra dimensión. Horacio no puede evitar la llamada argentina en Rayuela. Ha seguido la admonición de Apolinaire convertida en epigrafe: "hay que salir de casa para amarla". También lo ha perseguido la maldición de Vaché: "nada mata más a un hombre que tener que representar a un pais". Al mismo tiempo, le recuerda una voz que "era porteño, era clase media, era colegio nacional, y esas cosas no se arreglan así no más". Regresa, como también lo hace su apéndice en "El otro cielo" de Todos los fuegos el fuego: su libertad parisina se desmorona con la tendición. Juan, el intérprete argentino de 62. Modelo para armar, ${ }^{15}$ parece conseguir cierto equilibrio que, a lo sumo, es 10 máximo que logran todos los personajes que intentan el paso: movimiento pendular entre dos continentes, sin lograr encontrar lo que creían perdido en la Argentina que rechazaban por diversos motivos. Cortázar duda ante las fotografías que comenta y se declara contagiado por el mismo mal: "Pero el testigo que ve y dice verdad, ¿no será justamente el fantasma entre dos zonas, el vigía entre sueño y despertar? (p. 20). Son las mismas dos zonas en las que se mueve Alina Reyes, Horacio, Víctor y Juan.

\section{Regreso}

Autor y personajes ("Torito", "El móvil" -Final del juego- y los mencionados) están atacados de una profunda nostalgia: "Lo que ahora ve, fumando al borde de cualquiera de estas imágenes, ¿será todavía lo que quedó a su espalda una noche de noviembre del cincuenta y uno?" (p. 22). El autor contempla escenarios que se parecen a los que dejó, pero que presume que algo han cambiado: niños, "plazas, el Riachuelo, los Particulares Livianos. Cortázar incluye su poema en que expresa su recuerdo por la Cruz del Sur, los versos evocativos de una esquina solitaria, y trata de jsutificarse por su vuelta literaria a los mismos escenarios: " $¿$ Con qué derecho se entra a la ciudad que es sueño y es distancia, simulacro de reflejos?" (p. 45), para afirmar que a Buenos Aires puede irse de muchas maneras: "También yo la invento desde aquí, desde fuera como cualquier otro, más cerca quizá que otros" (p. 46). En contra de las frecuentes criticas exigiendo residencia obligatoria, Julio Cortázar responde firmemente: "De alguna manera, aunque pocos lo comprendan, él sabe ahora que nunca se fue de su ciudad, que se buscó a sí mismo para encontratla mejof" (p. 25). En forma

$1^{15}$ Buengos Aires: Sudamericana, 1968, 
similar, Horacio nunca se va de Buenos Aires en sus vicisitudes de Rayuela: queda Traveler, su doble y amigo, espetando en la orilla $y$ continuando su existencia porteña. También queda el hermano de Víctor, Nico, resucitado por el etror de las "Cartas de mamá". En el Buenos Aires anterior al peronismo también está el protagonista de "El otro cielo": sus andanzas europeas y. decimonónicas de nada le sirven. A todos ellos, una vez desaparece la otra realidad que les proporciona el desarraigo, ¿qué les resta en la Argentina? ¿Qué les ofrece la tierra cuando, voluntaria u obligadamente, tienen que aferrarse a ella?

\section{SOLEDAD}

La soledad reina libremente en las primeras obras del autor. Lo que puede calificarse como periodo predominantemente fantástico rezuma sensación solitaria. Presencia $a^{16}$ y Los reyes prolongan la encerrona de "Casa tomada" y "Bestiario". Tras el cambio de residencia del autor, los desafortunados protagonistas de "Axolotl" (Final del juego) y "Las armas secretas" van en busca de sus semejantes sin que lleguen a la esperanza de "El perseguidor" (Las armas secretas). Los premios colocan a una veintena de porteños en la cárcel simbólica de sus existencias y en $R a$ yuela Horacio y Traveler pasan de un circo a ser guardianes de. un manicomio, tras el fracaso de Horacio en París: el final tiene como escenario la habitación del primero, aislado tras su propia obcecación. En 62. Modelo para armar son todos los personajes los que parecen atacados por el mismo mal, al igual que los seres que pueblan "Todos los fuegos el fuego" o "La isla a mediodia". A todos ellos-los ve también reunidos el autor en una de las fotografías: "este hombre que a la altura de Talcahuano y Corrientes mira las luces de un café que no conoció nunca, se acerca a una mujer que no le tenderá la mano" (p. 20). Como el ser retratado por Scalabrini Ortiz, también está vapuleado por un viento de tarde, y trata de guarecerse de la vida inhóspita que le ofrece la ciudad. Como ulterior solución se encierra en sí mismo: "Y está el que no comulga, el que prefiere vivir vicariamente las ceremonias y los sacrificios de la ciudad, el que no presta la casa para hacer. otro ladrillo en la alta pasión de la muchedumbre. Alienado por la ausencia, nada lo distingue en el fondo de los otros; Buenos Aires le cede sus cafés, sus diarios, sus cines y sus tadios" (p. 52). Ya no lę

19 Buenos Aires: El Bibliófilo, 1938. 
queda más que el refugio del café porque le han fallado estrepitosamente varios intentos de comunicación o simulacros.

Cortázar teme la desaparición de la gran poesía popular; el tango, expresión genuina del porteño entra en estas páginas con la más clara alusión al libro de Scalabrini Ortiz: "El familiar volverá a perderse por el centro o los suburbios silbando el tango que ya no es compañero irónico de hombre solo entre gente sola" (p. 25). Este canto ya había hecho tímida aparición en "Relato con un fondo de agua", pero sobre todo en lo que tiene de pendencia con "Los amigos" y "El móvil", para ganar en humanidad con "Torito" (Final del juego) y su recuerdo de Justo Suárez y Carlos Gardel. En Rayuela, el tango cobra dimensiones universales con la nostalgia, la tristeza y la soledad del transterrado argentino. $\mathrm{La}$ efigie de Gardel se enseñorea de las imágenes que engarzan los textos de Buenos Aires. Buenos Aires: un retrato junto al limpiabotas, la tumba del cantante, su presencia eterna en la ciudad: "Cuándo, mi vida, cuándo" (p. 197).

En la obra de Cortázar se observan también los intentos del pueblo joven por innovar la lengua heredada: el glíglico de Rayuela y los cronopios, al igual que los diálogos de Calac y Polanco en 62. Modelo para armar tienen mucho de lunfardo y vesre porteño. Aquí es suave el juego: "Este que vive de su sueldo / ese que sueda de su vive" (p.) 197). Seres herméticos las más de las veces, en determinadas circunstancias los porteños de Cortázar gritan, no hablan: les toca a los componentes de la clase proletaria el personificar el intento. En Los premios, Presutti y su familia gritan constantemente y Cortázar les dedica nuevo homenaje en este libro con fotografías porteñas: "domingo porteño es ese camión donde los muchachos instalan a mamá y a tía, ponen el cajoncito de cerveza y los chorizos para la parrillada, la sandia, la radio, entre discusiones y silbidos y Dios querido carpeteá esa nube, a ver si ahora llueve cuando estábamos fenómeno" (p. 148). El domingo es el día que le queda al habitante de la megalópolis enajenado por la rutina de la semana, y se lanza al estadio, a las carreras, para seguir estando solo entre los miles que también quieren estar solos: grita más y nadie lo oye.

Como al resto de la tradición literaria argentina, a los personajes de Cortázar también los ataca el mal de la falta de complementación: el hombre no consigue la ansiada compañera. $\mathrm{L}_{a}$ mujer se convierte en símbolo de búsqueda con Celina en "Las puertas del cielo" y con la Maga en Rayuela; no pasa de intento su liberación en Los premios para Clau.

17 Buenos Aires: Angel Gulab, 1949; 
dia. Poca es la esperanza que le concede Cortázar en 1968: "Buenos Aires inventa sus mujeres, las confina irónicamente en el barrio donde han nacido y donde eligieron el shampoo y el marido. Los cruces y la propiedad siguen siendo horizontales" (p. 114). La sociedad parece que evita la unión profunda entre un hombre y una mujer; cuando el mundo parece que se para en su movimiento, algún resquicio se vislumbra:

Son los amantes, su isla flota a la deriva hacia muertes de césped, hacia puertas que se abren entre sábanas (p. 208).

Pero, tras la vuelta a la cotidiana obligación, el sueño se desvanece:

Ya están vestidos, ya se van por la calle

$Y$ sólo entonces

cuando están muertos, cuando están vestidos, que la ciudad los recupera hipócrita

y les impone los deberes cotidianos (p. 208).

Ante este continuo panorama de desamparo y soledad ciudadana, el individuo urbano deja caer su guardia y se entrega a la contemplación. Las medidas convencionales nada significan en estas circunstancias: "El tiempo es ese gris compadre pitando alli sin hacer nada" (p. 21). El espacio nada importa y el hombre se convierte en eterno aficionado en Los premios (Medrano) y Rayuela (Horacio y Traveler) y está atenazado por un mítico inmovilismo en " $\mathrm{La}$ banda" $\mathrm{y}$ "Las ménades": desearian rebelarse contra el ambiente, pero no lo hacen.

\section{Ei. Humor, el "otro" y la AMistad}

El arma más poderosa que le queda al autor, y que usa con gran eficacia, es el humor, "Torito", Los premios y. Rayuela equilibran la congoja de sus personajes con una dosis certera de humor porteño: sarcástico, algo cruel, agudo y también ingenuo. La vuelta y Ultimzo rount ${ }^{18}$ muestran la maestria de Cortázar al máximo una vez que ya no está sujeto a un género literario tradicional. El humor cortazariano en Buenos Aires. Buenos Aires se ha tornado suave, tierno, amigable: "Corrientes inconcebibles hoy con sus orquestas de señoritas, sus cines lar-

\footnotetext{
18 México: Siglo XXI, 1969.
} 
gos y estrechos y una pantalla neblinosa donde personajes de barba $y$ levita corrian por salones lujosos a pobres chicas con sombreritos y tirabuzones y a eso le llamảban peliculas realistas y entrada cero setenta" (p. 46). O bien: "De los porteños se podrá decir que no hemos hecho gran cosa y a lo mejor es cierto, pero nadie nos quita la fiaca, madre de la poesía, amiga de la silla en la vereda $y$ de tanto mate amargo" (P. 88), con lo que el autor vuelve a la justificcaión de su no muy nutrida obra literaria.

Ahora bien, el mecanismo que viene a salvar a sus personajes de la situación solitaria es mucho más complejo que los meros intentos anteriormente mencionados. El ser humano en esas circunstancias procede a la creación de un ser gemelo con el que se complementa: del rol, que le sirve para sobrevivir en la sociedad, pasa a un tercer ser que cree imaginar. En medio de los dos está el hombre incólume que continúa siendo él mismo. Ante la imposibilidad física de llegar a ser otra persona, Alina Reyes ("Lejana") es el primer ejemplo claro de doble en la obra de Cortázar: protagonista e ilusión consiguen unirse para llegar a la destrucción. "Las puertas del cielo" nos muestran el primer ensayo de unión, no ya de ser real e ilusión, sino de dos hombres - Marcelo y Mauro- en su mirada. "Axolotl" es más ambicioso: hombre y bestia. La nostalgia del transterrado consigue la reaparición en "Cartas de mamá", para resultar la causa de la destrucción en "Las armas secretas". En "El perseguidor" adquiere verdaderas dimensiones humanas para tener golpe certero en Rayuela: Horacio Oliveira se complementa en su amigo Manolo Traveler: su doble porteño que sigue la existencia argentina mientras él deambulaba por Francia. Tres nuevos fracasos en tres cuentos de Todos los fuegos el fuego, en la narración del mismo título, " $L_{a}$ isla a mediodía" y "El otro cielo", dejan paso a una multiplicación del doble en 62. Modelo para armar: la figura es la unión de todos los personajes en uno solo.

Significativamente, los mismos ejemplos muestran la aparición en la obra de Cortázar de un elemento importantísimo, ausente en las primeras obras: la amistad. Es en "Las puertas del cielo" donde las acciones del amigo casi salvan al protagonista de la destrucción y son más tarde los cronopiost9 quienes nos dan un resquicio de esperanza. "Los amigos" (Final del juego) muestran cómo, por encima de la rivalidad, todavía cuenta el recuerdo de la amistad de juventud. "Torito" es una lección de lealtad con el adversário. "El perseguidor", sin alcanzar fuerza decisiva, "es un nuevo escalón. Las àcciones de Medrano, Claudia y Pre-

79 Historias de cronopios y de famas (Buenos Aires: Minoțáuro, 1964), 
sutti (Los premios) salvan al resto del pasaje de su vulgaridad: solamente por amistad actúa el Pelusa y por impulso íntimo sale de su solitaria existencia Medrano. Sin embargo, en ningún momento en la obra de Cortázar alcanza la amistad tanta fuerza decisiva como en Rayuela. El hombre es solamente un ser igual al que se tiene delante: los errotes son circunstanciales en el amigo, no son el hombre mismo. De la locura quizá no se salve, pero de la destrucción lo rescata a Horacio la impresionante lealtad de Traveler. En la misma obra, Cortázar consigue unir las teorías literarias de Morelli, en busca de un lector que sea un amigo, junto al doble y el personaje solitario. Nuestro autor sigue recordando a su modo:

Extraño la Cruz del Sur

La Cruz del Sur el mate amargo

$y$ las voces de amigos

usándose con otros (p. 96).

Las imágenes fotográficas no pueden revivir el pasado, mucho más hondo que la superficie de las calles porteñas. Para Cortázar, lo que cuenta en verdad es "la interminable discusión sobre las cosas del cielo y de la tierra a lo largo de itinerarios y cigarrillos que entran hasta las dos o las tres de la mañana" (p. 28). Lo que permanece es la antigua amistad, un tanto mitificada por la tradición, el tango, la nostalgia de otros tiempos: una religión nacional a la que el argentino se aferra cuando las circuns* tancias de la vida se lo exigen.

\section{Futuro}

Julio Cortázar todavia ve otto resquicio para la soledad. El ejemplo nos lo da Presutti en Los premios: todo juventud, libre de inhibiciones, con puro pálpito porteño. El es el futuro de algún modo, él representa "la gente, la gente, razón de la ciudad de ese otro tiempo que vendrá con más justicia y más belleza, hermanos de un presente gris, semillas de futuro" (p. 25). Los niños han sido frecuentes personajes en la obra de Julio Cortázar: "Bestiario", "Los venenos", "Después del almuerzo", "Final del juego" nos muestran el mismo fracaso final que tiene Felipe en Los premios. Ahora bien, por Jorge, por pura amistad, por la fuerza del pálpito porteño, se mueve Presutti. Hacia los niños está la última mirada de Cortázar en Buenos Aires. Buenos Aires: 
Esos purretes que rien, ¿serán un día la gente que entra una vez más en el brete de los subtes, en el ir y venir del Buenos Aires cotidiano.

En sólo 20 sábados, como dice el cartel, en tantos otros 20 sábados, ¿cambiarán esas rosas por la espalda vencida del ciudadano camino del trabajo?

Pero arriba, más allá del último escalón, se adivina brillando el solo porteño, empieza la calle, sigue la vida (p. 224).

Para nuestro autor, de la esperanza de estos niños, la infancia de toda América, depende el porvenir de nuestras culturas. Seguir la senda marcada por Horacio-Traveler quizá los salve de la inanición ciudadana.

JOAQUÍN ROY-CABRERZO

Emory University. 